\title{
Identifying approaches for assessing methodological and reporting quality of systematic reviews: a descriptive study
}

Kusala Pussegoda', Lucy Turner ${ }^{1}$, Chantelle Garritty ${ }^{1,2}$, Alain Mayhew ${ }^{1}$, Becky Skidmore ${ }^{1}$, Adrienne Stevens ${ }^{1,2}$, Isabelle Boutron ${ }^{3}$, Rafael Sarkis-Onofre ${ }^{4}$, Lise M. Bjerre ${ }^{5,6,7}$, Asbjørn Hróbjartsson ${ }^{8}$, Douglas G. Altman ${ }^{9}$ and David Moher ${ }^{10^{*}}$ (D)

\begin{abstract}
Background: The methodological quality and completeness of reporting of the systematic reviews (SRs) is fundamental to optimal implementation of evidence-based health care and the reduction of research waste. Methods exist to appraise SRs yet little is known about how they are used in SRs or where there are potential gaps in research best-practice guidance materials.

The aims of this study are to identify reports assessing the methodological quality (MQ) and/or reporting quality (RQ) of a cohort of SRs and to assess their number, general characteristics, and approaches to 'quality' assessment over time.

Methods: The Cochrane Library, MEDLINE ${ }^{\oplus}$, and EMBASE ${ }^{\oplus}$ were searched from January 1990 to October 16, 2014, for reports assessing MQ and/or RQ of SRs. Title, abstract, and full-text screening of all reports were conducted independently by two reviewers. Reports assessing the $\mathrm{MQ}$ and/or RQ of a cohort of ten or more SRs of interventions were included. All results are reported as frequencies and percentages of reports.

Results: Of 20,765 unique records retrieved, 1189 of them were reviewed for full-text review, of which 76 reports were included. Eight previously published approaches to assessing MQ or reporting guidelines used as proxy to assess RQ were used in 80\% (61/76) of identified reports. These included two reporting guidelines (PRISMA and QUOROM) and five quality assessment tools (AMSTAR, R-AMSTAR, OQAQ, Mulrow, Sacks) and GRADE criteria. The remaining 24\% (18/76) of reports developed their own criteria. PRISMA, OQAQ, and AMSTAR were the most commonly used published tools to assess $\mathrm{MQ}$ or RQ. In conjunction with other approaches, published tools were used in 29\% (22/76) of reports, with 36\% (8/22) assessing adherence to both PRISMA and AMSTAR criteria and 26\% (6/22) using QUOROM and OQAQ.

Conclusions: The methods used to assess quality of SRs are diverse, and none has become universally accepted. The most commonly used quality assessment tools are AMSTAR, OQAQ, and PRISMA. As new tools and guidelines are developed to improve both the $\mathrm{MQ}$ and $\mathrm{RQ}$ of SRs, authors of methodological studies are encouraged to put thoughtful consideration into the use of appropriate tools to assess quality and reporting.
\end{abstract}

Keywords: Reporting quality, Methodological quality, Systematic reviews, Guideline adherence

\footnotetext{
* Correspondence: dmoher@ohri.ca

${ }^{10}$ Centre for Journalology, Canadian EQUATOR Centre, Clinical Epidemiology

Program, Centre for Practice-Changing Research, Ottawa Hospital Research

Institute, Ottawa, Ontario, Canada

Full list of author information is available at the end of the article
} 


\section{Background}

With the global annual expenditure of biomedical research estimated to be in excess of 100 billion USD [1], it is no surprise that the extent of published literature is growing each year, with PubMed $^{\oplus}$ housing over 24 million citations, for example [2]. Researchers and decision makers have recognized that although there are hundreds of thousands of studies of healthcare interventions, the quality of research and reporting is variable. Evidence indicates that unless research is adequately designed and reported, the resources invested in research are not used effectively [1]. One estimate suggests that at least $50 \%$ of published research studies were poorly conducted making them difficult to interpret and use to inform best practice [1].

Systematic reviews (SRs) are considered the gold standard for healthcare decision-making as they evaluate the quality and confidence of all of the available evidence addressing specific questions, such as the benefits and harms of specific health care interventions. When SR conduct is optimal, that is, when best practices are employed to minimize biases in the process of collecting, appraising, and synthesizing the evidence, researchers can best understand whether or not they can be confident in the findings [3, 4]. Further, when SR reporting is optimal, the essential information is presented for practice guideline developers and other stakeholders, such as policy makers and clinicians to facilitate translation into guidance and improved patient care.

Criteria for assessing the quality of primary research emerged in the late 1980s with the rise of evidencebased medicine. This set the stage for guidelines assessing quality of SR conduct to be developed. Several sets of criteria had been developed early on including Mulrow [5] and Sacks criteria [6]. It was not until Oxman and Guyatt developed the Overview Quality Assessment Questionnaire (OQAQ) [7] in 1991, that a validated tool for assessing methodological quality (MQ) existed for SRs of intervention studies. More than a decade after OQAQ, A Measurement Tool to Assess Systematic Reviews (AMSTAR) [8] was developed and validated in 2007 to address additional SR quality criteria including potential sources of bias that were not included in the OQAQ tool. In 2010, AMSTAR was revised (R-AMSTAR) to provide a quantitative scoring method to assess quality [9]. With criteria available for assessing SR conduct, it was apparent that SR authors address the standards for improving reporting quality (RQ) as well. In 1999, the Quality of Reporting of Metaanalyses (QUOROM) statement [10] was created to evaluate the completeness of reporting of meta-analysis of randomized trials. Subsequently, in 2009, QUOROM was updated as the Preferred Reporting Items of Systematic reviews and Meta-Analyses (PRISMA) statement [11] to address several conceptual and methodological advances in the conduct and reporting of SRs. The development and adoption of SR MQ and RQ tools aim to assess, and hopefully improve, the design, conduct, and reporting of SRs. Which tools are accepted and used by SR authors to assess MQ and completeness of reporting was unclear.

We set out to identify methodological evaluations assessing the MQ and/or RQ of SRs published from 1990 to 2014 in order to determine the approaches that were used.

\section{Methods \\ Definitions and important concepts}

We defined SRs and meta-analyses in line with that provided by the Cochrane Collaboration and the PRISMA statement [12, 13]. We adopted the term 'overview', to mean a summary of evidence from more than one SR, including the combination of different populations, different interventions, different outcomes (both favourable ones and adverse events), or different conditions $[14,15]$. It is synonymous with 'systematic review of systematic reviews', 'reviews of reviews', or an 'umbrella review'. We have included publications of 'methodological overviews', meaning research that has assessed the MQ and/or RQ of a cohort of SRs and refer to these publications simply as 'reports'.

\section{Methodological quality and completeness of reporting}

It is necessary to make clear the distinction between MQ and RQ. MQ addresses how well a SR was designed and conducted (e.g. literature search, selection criteria, pooling of data) [8]. RQ evaluates the description of the methodology and findings [11]. Moreover, to distinguish from MQ, the concept of risk of bias to assess primary studies is used to refer to systematic flaws or limitations in the design, conduct, or analysis of research that distort the findings [16]. Examples are the Cochrane Risk of Bias tool for randomized controlled trials [17], ROBINS-I for non-randomized studies [18], QUADAS-2 [19] for diagnostic studies, and ROBIS for SRs [16]).

\section{Objectives}

The objectives of this study are to identify reports assessing the MQ and/or RQ of SRs and to assess their general characteristics and approaches used.

\section{Eligibility criteria Inclusion criteria}

We included any methodological report published between January 1990 and October 2014 whose stated primary intent was to assess the quality of methodology, reporting, or other self-identified quality indicator(s) of a cohort of SRs of interventions. 


\section{Exclusion criteria}

We excluded reports of clinical interventions, whose primary intent was not to look at methodological quality or reporting and rather to summarise SR evidence for use in healthcare decision-making; reports assessing the quality of SRs of diagnostic, screening, etiological, or prognostic studies only; and evaluations of SRs that include study designs other than randomized controlled trials such as, narrative reviews, rapid reviews, network meta-analyses, and editorials. Reports in languages other than English were excluded due to budget constraints (Additional file 1) [20-31]. Reports assessing fewer than 10 SRs, those whose aim was to assess the reliability of an assessment tool, those assessing SRs in relation to one methodological characteristic (e.g. search strategy only), or those only assessing SRs with pooled estimates of effect, were also excluded.

\section{Search methods}

An experienced information specialist developed and conducted an extensive search of the Cochrane Library, $\mathrm{EMBASE}^{\circ}$, and Ovid MEDLINE, including In-Process \& Other Non-Indexed Citations, from January 1990 to May 23, 2012. All searches were updated on October 16, 2014. Potentially eligible titles and/or abstracts were identified using a combination of subject headings (e.g. 'Meta-Analysis as Topic,' 'Quality Control,' 'Checklist') and key words (e.g. 'umbrella review', scoring, compliance) (see Additional file 2). A second senior information specialist peer reviewed prior to execution [32]. Additional reports eligible for inclusion were identified by members of the research team prior to the start of the project and used as 'seed' articles when developing the electronic search strategy [33-35].

\section{Screening}

Titles and abstracts were screened for potentially inclusion using a liberal accelerated approach (i.e. one reviewer to include and two reviewers to exclude) [36]. Screening of full-text reports was completed independently in duplicate by a team of reviewers with experience in methodological reviews; $5 \%$ of potentially relevant articles were pilot tested. All screening disagreements were discussed, with any outstanding disagreements resolved by an independent third reviewer (DM). Data Management software, DistillerSR $^{\circ}$ [37], was used to manage retrieved records, screen reports, identify and track disagreements, and store data extracted. Results of the screening process are reported using a PRISMA flow diagram (Fig. 1).

\section{Data extraction}

We developed standardized forms for data extraction of items of interest from the included reports. General characteristics and full data extraction was conducted by two reviewers in duplicate; a $10 \%$ random sample of reports was assessed for accuracy. A pre-extraction meeting was held for each extraction stage along with pilot testing to ensure consistency across reviewers. The following general characteristics were extracted: year of publication; number of included SRs; specified medical area; databases searched; language restrictions; SR definition; reporting of availability of study protocol; and source of funding. The method of assessing MQ or RQ of SRs was extracted. Additional items pertaining to the evaluated reviews were extracted including the following: types of publishing journals; Cochrane or non-Cochrane review; conflict of interest; number of SRs reported as updated reviews; number of SRs discussing limitations; critical appraisal of abstracts; number of SRs reporting meta-analysis; methods of meta-analysis used in the SRs (e.g. methods used for meta-analysis and type of measure, details of investigation of publication bias, whether or not heterogeneity was reported as assessed); whether interpretation were consistent with results; and whether a quantitative summary of quality was provided.

The attributes of primary of interest were to identify the method or tool used to assess (a) MQ of SRs (e.g. use of AMSTAR) and (b) RQ of SRs (e.g. use of PRISMA, identification of key methodological items). We classified tools/ criteria into two groups: (1) items obtained from existing, published tools and (2) those developed by the report authors for their assessment.

Adherence data in relation to the MQ and RQ criteria were also extracted from those reports that provided it and are reported in a separate manuscript [38].

\section{Analyses}

Summary statistics are reported as frequency and percentage of reports. No formal inferential statistical analyses were conducted. A post hoc decision was made to look at publications by their intent to assess MQ only, RQ only, or both MQ and RQ. This decision was made in order to identify all methods or tools used by overview authors to assess methodological conduct or reporting. In addition, we can identify whether the appropriate methods or tools were used to assess MQ or RQ of SRs. Differences in SR characteristics such as funding, limitations, and language restrictions whose intent was to assess MQ or both MQ and RQ can also be determined. This decision was made without prior review of the data by one of us (DM).

\section{Results}

Of 20,765 unique title and abstract records retrieved and screened, 1189 full-text reports were reviewed for eligibility, of which 935 were excluded for not assessing a cohort of SRs or the primary intent was not to assess MQ or RQ. A secondary, full-text review of 254 remaining reports was carried out to ensure all exclusion 


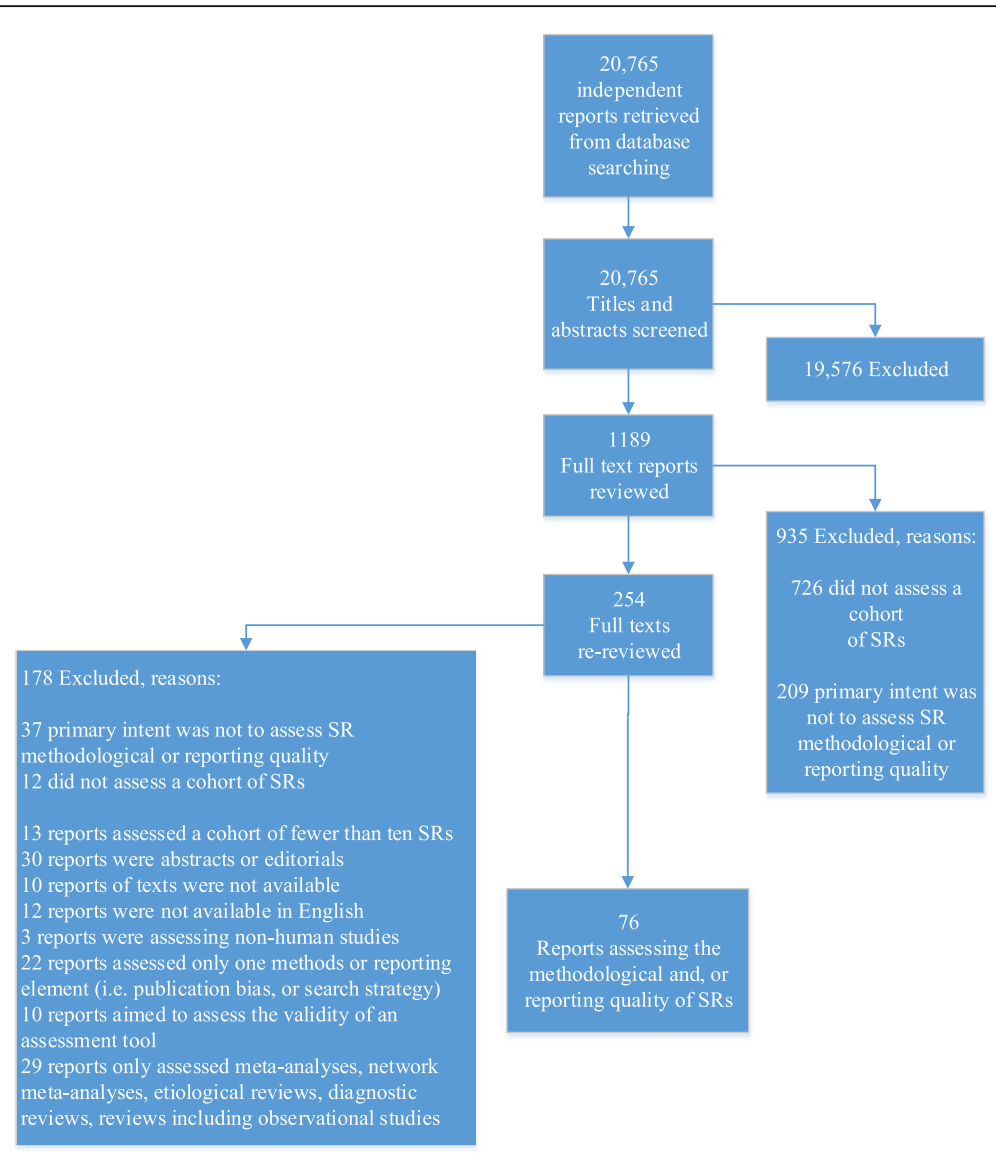

Fig. 1 Flow of study reports

criteria were met. A total of 76 reports were included (Fig. 1; see Additional file 3).

\section{Report characteristics}

Characteristics of included reports are shown in Table 1. Of the 76 included reports, 66\% (50/76) of them had a primary intent to assess MQ only, while the remaining one-third had a primary intent to assess either both MQ and RQ or RQ only; the latter two categories were grouped together, post hoc, given six reports (8\%) assessed RQ only. Reports spanned a 21-year period; half were published between 2010 and 2014, indicating a marked increase in more recent years. A median of 51 SRs (interquartile range 25 to 105 ) were assessed in reports. SRs assessed were published within a specific medical field in $87 \%(66 / 76)$ of reports. Included SRs were reported to be of interventions in medical fields such as orthodontics, food and beverage, pediatrics, nephrology, and dermatology; there were no predominant fields. SRs were mainly from a general sample of reviews across medical journals; 7\% (5/76) of reports evaluated a cohort of Cochrane reviews only. The majority of reports provided their source of SRs, whether via database searches or specific journals. Forty-one percent of reports did not report whether language restrictions were used, whereas the remaining 59\% were nearly evenly divided as to whether they did or not. SR defined for inclusion criteria were provided by nearly $30 \%$, while $43 \%$ used 'systematic review' as a search term, and $26 \%$ did not report this information. Few reports made reference to an available protocol. Thirty-nine percent of reports did not report the source of financial support for their research.

\section{Characteristics of SRs included in reports}

Information reported by reports about included SRs is shown in Table 2. More than half (44/76) of reports reported information on the review's source of funding, of which most (35/44) did so as part of their tool assessment. Conflict of interest information was reported in $45 \%(34 / 76)$ of reports in relation to a published tool assessment, whereas three reports did so as a stand-alone quality item. Heterogeneity assessment in reviews was considered as a marker for 'quality' in $62 \%(47 / 76)$ of reports, and 13\% (10/76) reported this information as part of a published tool. Forty-two percent of reports stated 
Table 1 Table of characteristics of reports presented by methodological quality or both methodological and reporting quality

\begin{tabular}{|c|c|c|c|c|}
\hline \multirow[t]{2}{*}{ Characteristic } & \multirow[t]{2}{*}{ Categorization } & \multirow{2}{*}{$\begin{array}{l}\text { Reports assessing } \\
\text { MQ only } \\
N=50, n(\%)\end{array}$} & \multirow{2}{*}{$\begin{array}{l}\text { Reports assessing } M Q \\
\text { and } R Q \text { or RQ only } \\
N=26, n(\%)\end{array}$} & \multirow{2}{*}{$\begin{array}{l}\text { All reports } \\
N=76, n(\%,\end{array}$} \\
\hline & & & & \\
\hline \multirow[t]{2}{*}{ Year of publication } & 1993-2009 & $26(52)$ & $11(42)$ & $37(49)$ \\
\hline & 2010-2014 & $23(46)$ & $16(62)$ & $39(51)$ \\
\hline \multirow[t]{2}{*}{ Number of assessed SRs } & Median (IQR) & $43(21,88)$ & $68(36,109)$ & $51(25,105)$ \\
\hline & Range & $10-327$ & $10-487$ & $10-487$ \\
\hline \multirow[t]{2}{*}{ Were SRs of particular medical field? } & Yes & $45(90)$ & $21(81)$ & $66(87)$ \\
\hline & No & $5(10)$ & $5(19)$ & $10(13)$ \\
\hline \multirow[t]{3}{*}{ Cohort of Cochrane SRs } & Cochrane only & $2(4)$ & $3(12)$ & $5(7)$ \\
\hline & Sample of reviews & $23(46)$ & $10(38)$ & $33(43)$ \\
\hline & Specific journal sample or other & $25(50)$ & $13(50)$ & $38(50)$ \\
\hline \multirow[t]{10}{*}{ Number of databases searched } & 1 & $9(18)$ & $8(31)$ & $17(22)$ \\
\hline & 2 & $5(10)$ & $2(8)$ & $7(9)$ \\
\hline & 3 & $7(14)$ & $2(8)$ & $9(12)$ \\
\hline & 4 & $7(14)$ & $5(19)$ & $12(16)$ \\
\hline & 5 & $5(10)$ & $3(12)$ & $8(11)$ \\
\hline & 6 & $2(4)$ & $2(8)$ & $4(5)$ \\
\hline & 7 & $5(10)$ & $1(4)$ & $6(8)$ \\
\hline & $8+$ & $3(6)$ & $1(4)$ & $3(4)$ \\
\hline & Not reported & $4(8)$ & $0(0)$ & $4(5)$ \\
\hline & Not applicable (select journals) & $3(6)$ & $3(12)$ & $5(7)$ \\
\hline \multirow[t]{4}{*}{ Reports restricting SRs by language } & No restrictions & $14(28)$ & $6(23)$ & $20(26)$ \\
\hline & Restricted to English & $14(28)$ & $4(15)$ & $18(24)$ \\
\hline & $\begin{array}{l}\text { Restricted to English and another } \\
\text { specified languages }\end{array}$ & $4(8)$ & $3(12)$ & $7(9)$ \\
\hline & Not reported & $18(36)$ & $13(50)$ & $31(41)$ \\
\hline \multirow[t]{5}{*}{ SR defined for inclusion criteria? } & Yes, but no reference given & $5(10)$ & $6(23)$ & $11(15)$ \\
\hline & $\begin{array}{l}\text { 'Systematic review' reported as a } \\
\text { search term }\end{array}$ & $21(42)$ & $12(46)$ & $33(43)$ \\
\hline & Cochrane collaboration and PRISMA Statement & $4(8)$ & $5(19)$ & $9(12)$ \\
\hline & Other reference & $3(6)$ & $0(0)$ & $3(4)$ \\
\hline & Not reported & $17(34)$ & $3(12)$ & $20(26)$ \\
\hline \multirow{3}{*}{$\begin{array}{l}\text { Was a study protocol reported as } \\
\text { available for this report? }\end{array}$} & Yes, link reported & $1(2)$ & $2(8)$ & $3(4)$ \\
\hline & Yes, upon request & $6(12)$ & $2(8)$ & $8(11)$ \\
\hline & No or not reported & $43(86)$ & $22(85)$ & $65(86)$ \\
\hline \multirow[t]{4}{*}{ Report Source of funding } & Industry Funded & $2(4)$ & $0(0)$ & $2(3)$ \\
\hline & Non-profit Funding & $21(42)$ & $14(54)$ & $35(46)$ \\
\hline & Reported no funding & $6(12)$ & $3(12)$ & $9(12)$ \\
\hline & Not reported & $21(42)$ & $9(35)$ & 30 (39) \\
\hline
\end{tabular}

$M Q$ methodological quality, $R Q$ reporting quality

how many of the included reviews had reported conducting a meta-analysis. Seventeen percent (13/76) reported which SRs were updates of an original review. Half of the reports extracted whether or not reviews considered issues of publication bias (formally or informally). Limitations were described in half $(14 / 26)$ of the reports whose primary intent was to assess MQ and $R Q$, whereas only $4 \%(2 / 50)$ reported this information in reports whose intent was to assess MQ only. Critical appraisal of SR abstracts was reported in 29\% (22/76) of 
Table 2 Information reported by reports about included SRs

\begin{tabular}{|c|c|c|c|}
\hline \multirow[t]{2}{*}{ Assessment of characteristics at the report level } & \multirow{2}{*}{$\begin{array}{l}\text { Reports assessing } \\
\text { MQ only } \\
N=50, n(\%)\end{array}$} & \multirow{2}{*}{$\begin{array}{l}\text { Reports assessing } M Q \\
\text { and } R Q \text { or RQ only } \\
N=26, n(\%)\end{array}$} & \multirow{2}{*}{$\begin{array}{l}\text { All reports } \\
N=76, n(\%)\end{array}$} \\
\hline & & & \\
\hline Source of funding & $25(50)$ & $19(73)$ & $44(58)$ \\
\hline Conflict of interest & $22(44)$ & $12(46)$ & $34(45)$ \\
\hline Heterogeneity investigated & $32(64)$ & $15(58)$ & $47(62)$ \\
\hline Meta-analysis results reported & $22(44)$ & $10(38)$ & $32(42)$ \\
\hline Updated reviews & $6(12)$ & $7(27)$ & $13(17)$ \\
\hline Publication bias & $25(50)$ & $13(50)$ & $38(50)$ \\
\hline Limitations discussed & $2(4)$ & $14(54)$ & $16(21)$ \\
\hline Critically appraised abstracts & $0(0)$ & $22(85)$ & $22(29)$ \\
\hline Interpretation consistent with results & $21(42)$ & $8(31)$ & $29(38)$ \\
\hline $\begin{array}{l}\text { Provided quantitative summary of quality or reporting } \\
\text { across reviews }\end{array}$ & $29(58)$ & $16(62)$ & $45(59)$ \\
\hline
\end{tabular}

$M Q$ methodological quality, $R Q$ reporting quality

reports, all of whose primary intent was to assess $\mathrm{MQ}$ and RQ. Thirty-eight percent of reports (29/76) gave consideration to how consistent review results were with review conclusions. A quantitative summary of SR quality across items or criteria were provided in 59\% (45/76) of reports. The largest difference between reports with the intent to assess MQ only and MQ and RQ is the critical appraisal abstracts and limitations. This is likely attributed directly to the structure of RQ guidelines (e.g. PRISMA and QUOROM) specifically including reporting items for abstracts and limitations whereas MQ tools (e.g. OQAQ and AMSTAR) do not (Table 2).
Use of published assessment tools to assess quality over time

We assessed how frequently the published assessment tools were used across reports, in 5-year increments after 1999 (Fig. 2). For MQ, AMSTAR (27 reports) [8] and OQAQ (26 reports) [7] were used the most often in reports; others used R-AMSTAR (3 reports) [9], Mulrow criteria (2 reports) [5], Grading of Recommendations Assessment, Development, and Evaluation (GRADE) criteria (2 reports) [39], and Sacks criteria (1 report) [6]. We observed that although OQAQ (1991) use for MQ decreased after 2009, it was still being used despite the

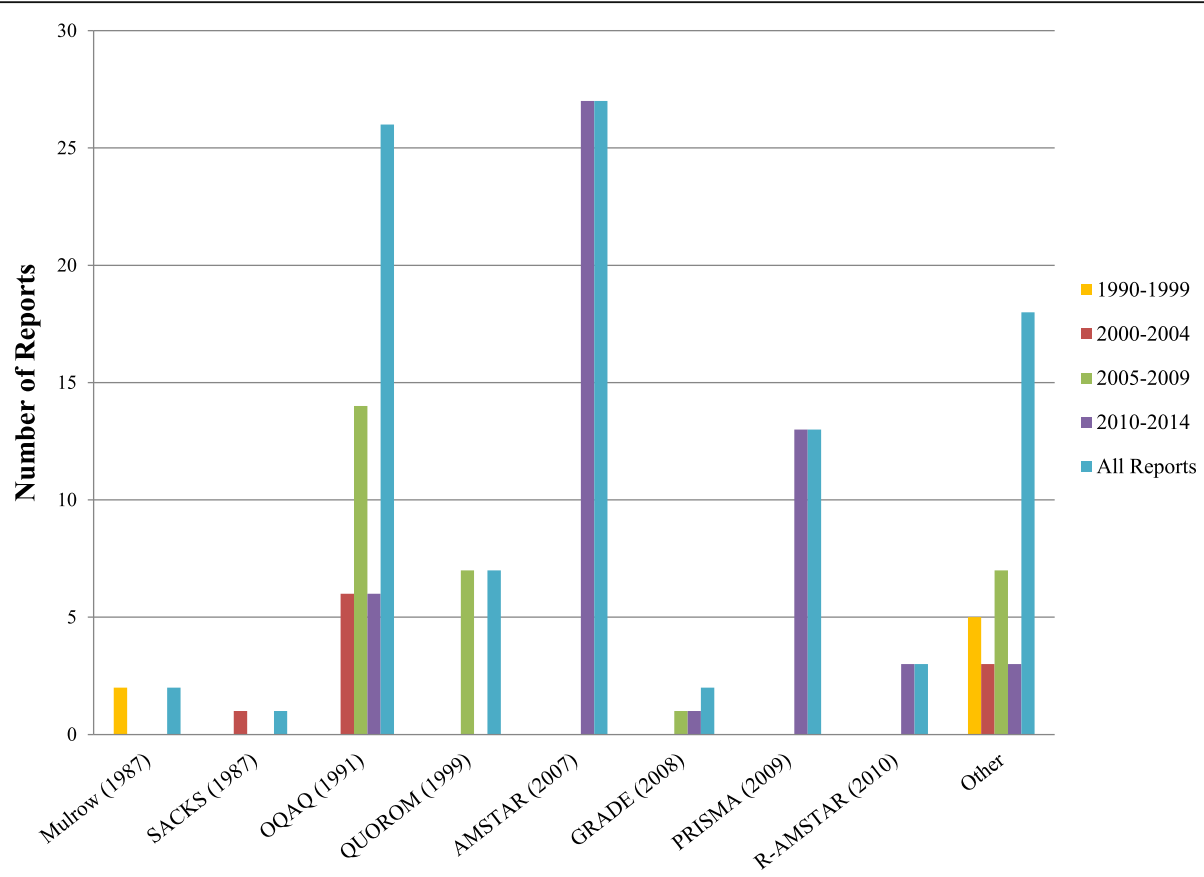

Fig. 2 Tools or other criteria used by reports to assess SR quality or reporting over time 
availability of AMSTAR as of 2007 (10 [after 2010] vs. 16 [before 2010]). For RQ, PRISMA (13 reports) [11] was used more often than its predecessor QUOROM (7 reports) [10]. No reports used QUOROM (1999) to assess RQ after PRISMA (2009) guidelines were published. In addition, several reports used their own criteria to assess quality after 2000, although OQAQ (1991) and QUOROM (1999) guidelines were available.

The above eight published tools were used across $80 \%$ (61/76) of reports. These reports used those tools alone, in combination with other tools or in combination with self-specified criteria. The remaining 15 reports used only self-specified criteria to assess quality.

Published assessment tools used alone or in combination with other criteria to assess quality

Thirty-nine (51\%) reports used published tools alone to assess quality (Fig. 3). Mulrow, GRADE, and QUOROM were used in one study each $(1 \% ; n=76)$. AMSTAR and OQAQ were used the most frequently as stand-alone means to assess quality in 21\% (16/76) and 20\% (15/76) of reports, respectively. PRISMA and R-AMSTAR were used alone in three $(4 \% ; n=76)$ and two $(3 \% ; n=76)$ reports, respectively.

In $29 \%(22 / 76)$ of reports, published tools or criteria were used in conjunction with other criteria or tools to assess MQ or RQ (Fig. 3). Of those assessing MQ and RQ, 36\% (8/22) used AMSTAR and PRISMA, 27\% (6/ 22) of reports used OQAQ and QUOROM, and 9\% (2/

22) of reports used OQAQ and PRISMA. The remaining reports used a variety of combinations: AMSTAR and RAMSTAR $(5 \% ; 1 / 22)$; OQAQ in conjunction with Sacks criteria (5\%; $1 / 22)$; AMSTAR and GRADE $(5 \% ; 1 / 22)$; a published tool (OQAQ or Mulrow) in combination with self-specified criteria $(9 \% ; 2 / 22)$; and AMSTAR in conjunction with OQAQ and self-specified criteria (5\%; $1 / 22$ ). No reports evaluated a combined approach for assessing RQ. Due to the number of different combinations of tools and criteria used to assess quality in reports, it was not conducive to separate by time as well.

\section{Self-specified criteria to assess quality}

Although OQAQ was published in 1991, authors developed their own criteria to assess MQ or RQ in $24 \%$ (18/ 76) of reports. Of these reports, 15 only used self-specified criteria to assess quality, and three reports used selfspecified criteria in combination with another tool (as described above).

Quality assessment criteria used in these reports varied considerably. Furthermore, 13 reports used their own criteria to assess quality after the publication of both OQAQ (1991) and QUOROM (1999). Seven of the 18 reports $(39 \%)$ did not provide any description of how they derived their quality assessment items. Of the remaining 11 reports, the majority were derived from the Oxman and Guyatt criteria. Two reports based criteria on Oxman and Guyatt, Jadad Scale (developed to assess primary studies), and QUOROM [40, 41]; one report on Oxman and Guyatt and the Jadad Scale [42]; two reports on Oxman and Guyatt and Mulrow [43, 44];

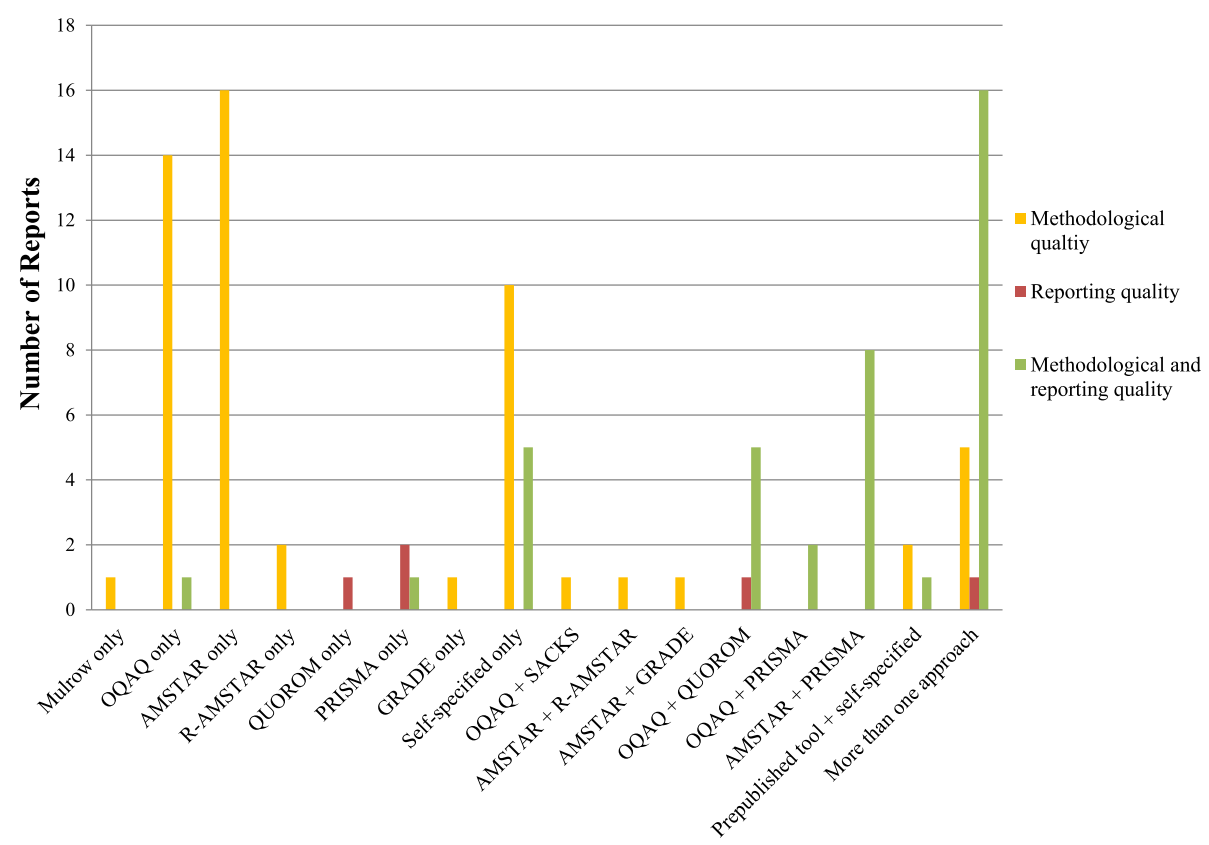

Fig. 3 Published tools or self-specified criteria used alone or in conjunction presented by reported intent 
one report on Oxman and Guyatt, Light and Pillemer, and Mulrow [45]; one report used Oxman Guyatt and five additional criteria [46]; one report used Rapid Appraisal Protocol (RAP), National Center for the Dissemination of Rehabilitation Research (NCDRR) [47]; one report was based on PRISMA [48]; one on PRISMA and QUOROM [49]; and one report was based on Oxman and Guyatt, Hoving scale, discussion between three reviewers and expectations discussed from SRs by Sackett and Seers [50].

Only four of the 18 reports (22\%) provided an explanation as to why they had created their own criteria. Two reports stated criteria was developed to evaluate quality of SRs in a specific medical field [40,51]; one report [44] published in 1996 stated there was no gold standard for assessing quality; another report stated their quality assessment scale was developed to specifically evaluate patellofemoral pain syndrome [46].

\section{Appropriate use of tools to assess quality of conduct vs. reporting of conduct}

We also assessed whether reports used the quality of methodological conduct (MQ) and reporting (RQ) tools appropriately. The majority of reports used the tools correctly (Fig. 3). However, we noted that several reports did not use the tools or criteria appropriately based on their reported or inferred intent. One report intended to assess both $\mathrm{MQ}$ and RQ but only used OQAQ criteria, a tool for assessing the quality of conduct. Another study intended to assess both MQ and RQ but only used PRISMA, a reporting guideline. Another report intended to assess RQ only and used both OQAQ and QUOROM which are tools used to assess quality of conduct and reporting of conduct. In addition, one report used GRADE to assess MQ.

\section{Discussion}

We identified 76 reports in the health care literature assessing the MQ and/or the RQ of SRs published in the last 24 years in order to assess their quantity, characteristics, and methodology over time. The number of such reports increased over time with two-thirds intending to assess MQ only and the remaining 34\% assessing either $\mathrm{RQ}$ only or both MQ and RQ. Although the number of reports increased, the criteria used to assess MQ and critical appraisal of SRs varied considerably across reports. Eight published tools were used in $80 \%$ of reports while review authors of the remaining reports only used their own criteria to assess quality. We identified PRISMA, AMSTAR, and OQAQ to be most commonly used tools.

This research parallels that of Dechartres et al. (2011), who investigated how quality is assessed in RCTs [52]. Those authors found great variety in how the quality of trials was assessed, from which the authors raised important issues about the tools and criteria that should be used to assess RCT methodological quality and reporting [53]. Although the diversity of assessment criteria and the number of scales used to assess RCT quality was greater, the authors found, as we did, that the number of methodological reviews had increased over time.

Our findings appear consistent with that of other research which suggests that tools used to assess MQ and RQ of SRs are variable [33, 54, 55]. In 2012, two studies were conducted to assess their methodological rigor $[56,57]$. The first concluded that PRISMA, OQAQ, and AMSTAR were the most frequent methods of critical appraisal and quality assessment for SRs and that inconsistency in how SR quality is assessed should be reviewed [56]. The second identified at least nine methods of assessing SR quality and called for further empirical evidence to support the conduct of overviews [57].

In addition, despite lack of available evidence, it would be feasible to suggest that risk of bias assessment criteria at the trial level over time may influence trial conduct. By extension, critical appraisal criteria for SRs over time may in turn influence SR conduct. A small body of literature has started to emerge with regard to biases within SRs which would influence results of overviews [58]. The SR community currently lacks clear guidance regarding best SR practices to minimize biases. Standardized tools/criteria would provide the foundation upon which to develop more consistent critical appraisal criteria for SRs, which in turn could influence SR conduct.

Approximately $20 \%$ of methodological reports included in our investigation did not report their intention to assess either MQ or RQ in the title. This may be simply poor reporting or may highlight the general confusion over assessing SR 'quality' versus reporting of conduct. Quality of conduct (MQ) tools were developed to assess how well a SR was designed and conducted whereas reporting (RQ) guidelines were designed to guide SR authors in appropriate reporting of methodology and findings of SRs $[8,11]$. The use of reporting guidance, such as PRISMA, to assess the methodological conduct or quality of SRs is not appropriate. While PRISMA serves as a resource to improve the quality of reporting of SRs, it is not an instrument to gauge the quality of a SR [59]. By extension, we also argue that the use of quality of conduct tools, such as OQAQ, to assess quality of reporting of SRs is not appropriate. While MQ criteria are important to improve quality of conduct, they do not assess quality of reporting [8]. Moreover, we also note that in one review, the authors inappropriately used GRADE and items from the Jadad Scale to assess MQ of SRs. GRADE was developed as a system for grading the quality of evidence of trials across studies for each important outcome, while the Jadad Scale was developed to assess the MQ/RQ of clinical trials assessing pain; thus, applicability to SRs is questionable [35, 60]. SR authors should adhere to MQ and RQ criteria to 
ensure high quality of conduct and accurate information is reported in SRs.

Methodologists focus on improving quality and reporting, and new tools and guidelines continue to be developed. For example, the US Institute of Medicine developed their own standards for assessing MQ in SRs and reporting [61]. Further, Cochrane recommends using the Methodological Expectations of Cochrane Intervention Review (MECIR) to guide conduct of Cochrane SRs for interventions [62]. Other recently published tools to improve quality in SRs include the Risk of Bias in Systematic Reviews (ROBIS) [16], developed to complement AMSTAR. The concept of risk of bias is distinct from MQ in that it assesses systemic flaws or limitations in the design, conduct, or analysis of research that distort the findings [16]. Although there is some content overlap between risk of bias and MQ criteria, the majority of criteria are distinct. For example, AMSTAR assesses whether at least two electronic sources were searched whereas ROBIS assesses whether the search included an appropriate range of databases for published and unpublished reports. Nonetheless, with the plethora of tools and guidance available, there remains confusion over the best criteria and tools to assess quality or reporting for consistent standards across reports. This may be simply due to SR authors being unaware of appropriate newer tools that exist; or tools or guidelines that have less criteria to assess are appealing simply due to lack of time; or they feel some criteria are lacking in the validated tools. Newer MQ and RQ tools such as AMSTAR and PRISMA were developed to reflect of the state of current SR methodology research. SR authors should put thoughtful consideration into use of appropriate MQ and RQ criteria to conduct their SR.

There are potential limitations to this study. All methodological research relating to the quality of studies, whether at the trial or SR level, is contingent upon the quality of reporting. In addition, due to feasibility, we have limited reports to English language only, reports assessing more than 10 SRs and reports using more than one methodology or reporting criteria to assess quality.

\section{Conclusions}

In conclusion, a body of literature exists in evaluating the quality and reporting of SRs across a variety of medical fields. How quality is assessed varies and is similar to the conclusions in other reports. As new tools and guidelines are developed to improve both the MQ and RQ of SRs, SR authors are encouraged to give careful thought to the use of the most current and appropriate tools to assess quality and reporting as they reflect the state of current SR methodology research.

\section{Additional files}

Additional file 1: List of non-English language studies [20-31]. (DOCX $15 \mathrm{~kb}$ )

Additional file 2: Search strategy. (DOCX $17 \mathrm{~kb}$ )

Additional file 3: List of included studies [33, 40, 42-51, 63-126]. (DOCX $22 \mathrm{~kb}$ )

\section{Abbreviations}

AMSTAR: A Measurement Tool to Assess Systematic Reviews; GRADE: Grading of Recommendations Assessment, Development, and Evaluation; MECIR: Methodological Expectations of Cochrane Intervention Review; MQ: Methodological quality; OQAQ: Overview Quality Assessment Questionnaire; PRISMA: Preferred Reporting Items of Systematic reviews and Meta-Analyses; QUOROM: Quality of Reporting Of Meta-analyses; RAMSTAR: Revised-A Measurement Tool to Assess Systematic Reviews; $\mathrm{RQ}$ : Reporting quality; SR: Systematic review

\section{Acknowledgements}

We would like to acknowledge Michelle Fiander for peer reviewing the search strategy. We would also like to thank Raymond Daniel for his support with running the search, identifying duplicates, and identifying studies for screening. We would like to thank Sophia Tsouros, Alexander Tsertsvadze, and Kavita Singh for their screening support.

\section{Funding}

This project was completed on behalf of the Cochrane Bias Methods Group, funded by Canadian Institutes of Health Research (CIHR reference no: CON-105529). The funder had no role in the design, conduct, and reporting of the project.

\section{Availability of data and materials}

Data are reported in the manuscript and additional files.

\section{Authors' contributions}

$D M$ and DGA conceived the project. IB, LB, CG, LT, AS, DGA, and DM developed the protocol for the project. BS developed the search strategy. LT, $\mathrm{KP}, \mathrm{AM}$, and RO screened studies and extracted data. LT compiled the data and drafted the first version of the report. BS derived the literature search strategy for the review. All authors commented on the data and reviewed the manuscript. All authors read and approved the final manuscript.

\section{Competing interests}

DM is co-editor in chief of Systematic Reviews and also received funding from BioMed Central for a separate project. AM worked for the Cochrane Methods Bias Group from September 2013 to September 2015 when he worked on this paper; the group was supported by the Canadian Institutes of Health Research (CIHR Funding Reference Number-CON-105529).

All other authors declare that they have no competing interests.

\section{Consent for publication}

Not applicable.

Ethics approval and consent to participate Not applicable.

\section{Publisher's Note}

Springer Nature remains neutral with regard to jurisdictional claims in published maps and institutional affiliations.

\section{Author details}

${ }^{1}$ Ottawa Methods Centre, Clinical Epidemiology Program, Centre for Practice-Changing Research, Ottawa Hospital Research Institute, Ottawa, Ontario, Canada. ${ }^{2}$ Translational Research in Biomedicine (TRIBE) Program, University of Split School of Medicine, Split, Croatia. ${ }^{3}$ INSERM, UMR 1153, Centre of Research in Epidemiology and Statistics Sorbonne Paris Cité, University Paris Descartes, Paris, France. ${ }^{4}$ Graduate Program in Dentistry, Federal University of Pelotas, Pelotas, RS, Brazil. ${ }^{5}$ Department of Family Medicine, University of Ottawa, Ottawa, Ontario, Canada. ${ }^{6}$ Bruyère Research Institute, Ottawa, Ontario, Canada. ${ }^{7}$ School of Epidemiology, Public Health 
and Preventive Medicine, University of Ottawa, Ottawa, Ontario, Canada. ${ }^{8}$ Center for Evidence-Based Medicine, University of Southern Denmark \& Odense University Hospital, Odense, Denmark. ${ }^{9}$ Centre for Statistics in Medicine, Nuffield Department of Orthopaedics, Rheumatology \& Musculoskeletal Sciences, University of Oxford, Oxford, UK. ${ }^{10}$ Centre for Journalology, Canadian EQUATOR Centre, Clinical Epidemiology Program, Centre for Practice-Changing Research, Ottawa Hospital Research Institute, Ottawa, Ontario, Canada.

\section{Received: 20 September 2016 Accepted: 31 May 2017}

Published online: 19 June 2017

\section{References}

1. Chalmers I, Glasziou P. Avoidable waste in the production and reporting of research evidence. Lancet. 2009;374(9683):86-9. PMID: 19525005.

2. National Center for Biotechnology Information. PubMed Help [Internet]. Available at: http://www.ncbi.nlm.nih.gov/books/NBK3827/. Accessed 14 Jan 2016.

3. Cook DJ, Mulrow CD, Haynes RB. Systematic reviews: synthesis of best evidence for clinical decisions. Ann Intern Med. 1997;126(5):376-80. PMID: 9054282.

4. The Cochrane Collaboration. Cochrane Handbook for Systematic Reviews of Interventions. Version 5.1.0. 2011 [updated March 2011].

5. Mulrow CD. The medical review article: state of the science. Ann Intern Med. 1987;106(3):485-8. PMID: 3813259.

6. Sacks HS, Berrier J, Reitman D, Ancona-Berk VA, Chalmers TC. Meta-analyses of randomized controlled trials. N Engl J Med. 1987;316(8):450-5. PMID: 3807986.

7. Oxman $A D$, Guyatt $G H$. Validation of an index of the quality of review articles. J Clin Epidemiol. 1991;44(11):1271-8. PMID: 1834807.

8. Shea BJ, Grimshaw JM, Wells GA, Boers M, Andersson N, Hamel C, et al. Development of AMSTAR: a measurement tool to assess the methodological quality of systematic reviews. BMC Med Res Methodol. 2007;7:10. PMID: 17302989.

9. Kung J, Chiappelli F, Cajulis OO, Avezova R, Kossan G, Chew L, et al. From systematic reviews to clinical recommendations for evidence-based health care: validation of revised assessment of multiple systematic reviews (R-AMSTAR) for grading of clinical relevance. Open Dent J. 2010;4:84-91. PMID: 21088686.

10. Moher D, Cook DJ, Eastwood S, Olkin I, Rennie D, Stroup DF. Improving the quality of reports of meta-analyses of randomised controlled trials: the QUOROM statement. Quality of Reporting of Meta-analyses. Lancet. 1999; 354(9193):1896-900. PMID: 10584742.

11. Moher D, Liberati A, Tetzlaff J, Altman DG. Preferred reporting items for systematic reviews and meta-analyses: the PRISMA statement. J Clin Epidemiol. 2009;62(10):1006-12. PMID: 19631508.

12. Liberati A, Altman DG, Tetzlaff J, Mulrow C, Gotzsche PC, loannidis JP, et al. The PRISMA statement for reporting systematic reviews and meta-analyses of studies that evaluate health care interventions: explanation and elaboration. Ann Intern Med. 2009;151(4):W65-94. PMID: 19622512.

13. Green $S$, Higgins JPT, Alderson $P$, et al. What is a systematic review? 1.2.2. [Internet]. Available at: http://handbook.cochrane.org/chapter_1/1_2_2_ what_is_a_systematic_review.htm. Accessed 27 Jan 2016

14. Smith V, Devane D, Begley CM, Clarke M. Methodology in conducting a systematic review of systematic reviews of healthcare interventions. BMC Med Res Methodol. 2011;11(1):15. PMID: 21291558.

15. Becker, LA and Oxman, AD. Chapter 22: Overview of reviews. [Internet]. Available at: http://handbook.cochrane.org/chapter_22/22_overviews_of_ reviews.htm. Accessed 14 Jan 2016.

16. Whiting P, Savovic J, Higgins JP, Caldwell DM, Reeves BC, Shea B, et al. ROBIS: a new tool to assess risk of bias in systematic reviews was developed. J Clin Epidemiol. 2016;69:225-34. PMID: 26092286.

17. Higgins JP, Altman DG, Gotzsche PC, Juni P, Moher D, Oxman AD, et al. The Cochrane Collaboration's tool for assessing risk of bias in randomised trials. BMJ. 2011;343:d5928. PMID: 22008217.

18. Sterne J, Higgins JPT, Reeves B, et al. A Cochrane Risk Of Bias Assessment Tool: for non-randomized studies of interventions (ACROBAT-NRSI). [Internet]. Available at: https://sites.google.com/site/riskofbiastool/welcome/ home/the-team. Accessed 14 Jan 2016.

19. Whiting PF, Rutjes AW, Westwood ME, Mallett S, Deeks JJ, Reitsma JB, et al QUADAS-2: a revised tool for the quality assessment of diagnostic accuracy studies. Ann Intern Med. 2011;155(8):529-36. PMID: 22007046.

20. Letelier L, Juan J, Manriquez M, Gabriel Rada G. Systematic reviews and metaanalysis: are the best evidence? Rev Med Chile. 2005;133:246-9.
21. Grootens K, Assendelft W, Overbecke A. Increased number of systematic reviews in the Netherlands in the period 1991-2000. [Dutch]. Ned Tijdschr Geneskd. 2003;147(45):2226-30.

22. Yan Y-Y, Yi Z-M. Publication and quality of systematic reviews/meta-analyses conducted by Hospital Pharmacists in China. Chin J Evid Based Med. 2012 12(1):92-7.

23. Gonzalez de Dios J. Checklist in systematic reviews and meta-analysis: the PRISMA statement, beyond the QUOROM. Aten Primaria. 2011;18(3):164-6.

24. Wang J, Lui Q, Weng C-G, Wang Y, Li L, Lie X, et al. Quality assessment for Chinese systematic reviews/meta-analyses in public health. Chin J Evid Based Med. 2010;10(12):1367-74.

25. Coenen M, Schuetz GM, Dewey M. Evaluating the methodologic quality of systematic reviews and meta-analyses. AMSTAR (A Measurement Tool for the Assessment of Multiple Systematic Reviews]. [German]. ROFO Fortschr Geb Rontgenstr Nuklearmed. 2013;185(10):937-40. PMID: 24490255.

26. Xu J, An N, Zhou W, Shi X, Liu Y, Liang L, et al. Methodological quality assessment of systematic reviews or meta-analyses of intervention published in the Chinese journal of evidence-based medicine. Chin J Evid -Based Med. 2013:13(5):605-11.

27. Wang Y-Q, Luo Q-Q, Li Y-P, Deng S-L, Li X-L, Wei S-Y. A systematic assessment of the quality of systematic reviews/meta-analyses in radiofrequency ablation versus hepatic resection for small hepatocellular carcinoma. Chin J Evid -Based Med. 2014;14(5):561-74.

28. Morichon A, Pallot A. Taping: trial by evidence? Review of systematic reviews. Kinesitherapie. 2014;14(147):34-66.

29. Liao X, Shen H, Xie Y-M. Literature review report on efficacy evaluation about Kudiezi injection. Zhongguo Zhongyao Zazhi. 2012;37(18):2810-3.

30. Chen M, He J, Xiao Y, Huang R, Zhou Z-F, Chen C-Y, et al. Status quo analysis on TCM systematic reviews/meta-analyses published in Chinese journals. Chin J Evid -Based Med. 2012;12(12):1526-30.

31. Jin $\mathrm{Y}-\mathrm{H}, \mathrm{Ma}$ E-T, Hua W, Dou H-Y. Reporting and methodological quality of systematic reviews and meta-analyses in nursing field in China. Chin J Evid -Based Med. 2012;12(9):1148-55.

32. Altman DG, Simera I, Hoey J, Moher D, Schulz K. EQUATOR: reporting guidelines for health research. Open Med. 2008;2(2):e49-50. PMID: 21602941.

33. Moher D, Tetzlaff J, Tricco AC, Sampson M, Altman DG. Epidemiology and reporting characteristics of systematic reviews. PLoS Med. 2007;4(3):e78. PMID: 17388659

34. Higgins J, Altman DG. Chapter 8: Assessing risk of bias in included studies. [Internet]. Available at: http://handbook.cochrane.org/chapter_8/8 assessing_risk_of_bias_in_included_studies.htm. Accessed 18 Dec 2013.

35. Jadad AR, Moore RA, Carroll D, Jenkinson C, Reynolds DJ, Gavaghan DJ, et al. Assessing the quality of reports of randomized clinical trials: is blinding necessary? Control Clin Trials. 1996;17(1):1-12. PMID: 8721797.

36. Khangura S, Konnyu K, Cushman R, Grimshaw J, Moher D. Evidence summaries: the evolution of a rapid review approach. Syst Rev. 2012;1:10. PMID: 22587960

37. Evidence Partners. DistillerSR [Internet]. Available at: https://www. evidencepartners.com/products/distillersr-systematic-review-software. Accessed 27 Jan 2016.

38. Pussegoda K, Turner L, Garritty C, Mayhew A, Skidmore B, Stevens A, Boutron I, Sarkis-Onofre R, Bjerre LM, Hrobjartsson A, Altman DG, Moher D. Systematic review adherence to methodological or reporting quality. Manuscript submitted for publication. Corresponding author Dr. David Moher.

39. Atkins D, Best D, Briss PA, Eccles M, Falck-Ytter Y, Flottorp S, et al. Grading quality of evidence and strength of recommendations. BMJ. 2004;328(7454): 1490. PMID: 15205295

40. Sheikh L, Johnston S, Thangaratinam S, Kilby MD, Khan KS. A review of the methodological features of systematic reviews in maternal medicine. BMC Med. 2007:5:10. PMID: 17524137

41. Sood A, Sood R, Bauer BA, Ebbert JO. Cochrane systematic reviews in acupuncture: methodological diversity in database searching. J Altern Complement Med. 2005;11(4):719-22. PMID: 16131298

42. Stroup DF, Thacker SB, Olson CM, Glass RM, Hutwagner L. Characteristics of meta-analyses related to acceptance for publication in a medical journal. J Clin Epidemiol. 2001:54(7):655-60. PMID: 11438405

43. Smith AF. An analysis of review articles published in four anaesthesia journals. Can J Anaesth. 1997:44(4):405-9. PMID: 9104524.

44. Hardern RD, Hamer DW. Reviews in accident and emergency medicine: the past and the future. J Accid Emerg Med. 1996;13(3):169-72. PMID: 8733650 . 
45. Assendelft WJ, Koes BW, Knipschild PG, Bouter LM. The relationship between methodological quality and conclusions in reviews of spinal manipulation. JAMA. 1995;274(24):1942-8. PMID: 8568990.

46. Barton CJ, Webster KE, Menz HB. Evaluation of the scope and quality of systematic reviews on nonpharmacological conservative treatment for patellofemoral pain syndrome. J Orthop Sports Phys Ther. 2008;38(9):529-41. PMID: 18758046

47. Pieper D, Mathes T, Eikermann M. Impact of choice of quality appraisal tool for systematic reviews in overviews. J Evid Based Med. 2014;7(2):72-8. PMID: 25155764.

48. Turner L, Galipeau J, Garritty C, Manheimer E, Wieland LS, Yazdi F, et al. An evaluation of epidemiological and reporting characteristics of complementary and alternative medicine (CAM) systematic reviews (SRs). PLoS One. 2013;8(1):e53536. PMID: 23341949.

49. Weir CR, Staggers N, Laukert T. Reviewing the impact of computerized provider order entry on clinical outcomes: the quality of systematic reviews. Int J Med Inform. 2012;81(4):219-31. PMID: 22342868.

50. McAlister FA, Clark HD, van Walraven C, Straus SE, Lawson FM, Moher D, et al. The medical review article revisited: has the science improved? Ann Intern Med. 1999;131(12):947-51. PMID: 10610646.

51. Knox EM, Thangaratinam S, Kilby MD, Khan KS. A review of the methodological features of systematic reviews in fetal medicine. Eur J Obstet Gynecol Reprod Biol. 2009;146(2):121-8. PMID: 19515478

52. Dechartres A, Charles P, Hopewell S, Ravaud P, Altman DG. Reviews assessing the quality or the reporting of randomized controlled trials are increasing over time but raised questions about how quality is assessed. J Clin Epidemiol. 2011;64(2):136-44. PMID: 20705426.

53. Schulz KF, Altman DG, Moher D. CONSORT 2010 statement: updated guidelines for reporting parallel group randomised trials. BMJ. 2010;340: C332. PMID: 20332509.

54. Ma IW, Khan NA, Kang A, Zalunardo N, Palepu A. Systematic review identified suboptimal reporting and use of race/ethnicity in general medical journals. J Clin Epidemiol. 2007;60(6):572-8. PMID: 17493512.

55. Brugha TS, Matthews R, Morgan Z, Hill T, Alonso J, Jones DR. Methodology and reporting of systematic reviews and meta-analyses of observational studies in psychiatric epidemiology: systematic review. Br J Psychiatry. 2012: 200(6):446-53. PMID: 22661677.

56. Pieper D, Buechter $R$, Jerinic $P$, Eikermann M. Overviews of reviews often have limited rigor: a systematic review. J Clin Epidemiol. 2012;65(12):1267-73. PMID: 22959594

57. Hartling L, Chisholm A, Thomson D, Dryden DM. A descriptive analysis of overviews of reviews published between 2000 and 2011. PLoS One. 2012; 7(11):e49667. PMID: 23166744.

58. Page MJ, McKenzie JE, Kirkham J, Dwan K, Kramer S, Green S, et al. Bias due to selective inclusion and reporting of outcomes and analyses in systematic reviews of randomised trials of healthcare interventions. Cochrane Database Syst Rev. 2014;10:MR000035. PMID: 25271098.

59. PRISMA: Transparent reporting of systematic reviews and meta-analyses. [Internet]. Available at: http://www.prisma-statement.org/. Accessed 14 Jan 2016.

60. Guyatt GH, Oxman AD, Vist GE, Kunz R, Falck-Ytter Y, Alonso-Coello P, et al. GRADE: an emerging consensus on rating quality of evidence and strength of recommendations. BMJ. 2008;336(7650):924-6. PMID: 18436948.

61. Institute of Medicine (US) Committee on Standards for Systematic Reviews of Comparative Effectiveness Research. Finding what works in health care: standards for systematic reviews. [Internet]. Available at: http://www.ncbi.nlm. nih.gov/pubmed/?term=24983062. [PMID:24983062] Accessed 12 Jan 2016.

62. Methodological Expectations of Cochrane Intervention Reviews (MECIR). [Internet]. Available at: http://methods.cochrane.org/mecir. Accessed 14 Jan 2016.

63. Al Faleh K, Al-Omran M. Reporting and methodologic quality of Cochrane Neonatal review group systematic reviews. BMC Pediatr. 2009:9:38. PMID: 19534780.

64. Anttila H, Samuelsson K, Salminen A, Brandt A. Quality of evidence of assistive technology interventions for people with disability: an overview of systematic reviews. Technol Disability. 2012;24:9-48.

65. Aziz T, Compton S, Nassar U, Matthews D, Ansari K, Flores-Mir C. Methodological quality and descriptive characteristics of prosthodontic-related systematic reviews. J Oral Rehabil. 2013;40(4):263-78. PMID: 23330989.

66. Barbosa FT, Castro AA, de Miranda CT. Neuraxial anesthesia compared to general anesthesia for procedures on the lower half of the body: systematic review of systematic reviews. Rev Bras Anestesiol. 2012;62(2):235-43. PMID: 22440378.
67. Biondi-Zoccai GG, Lotrionte M, Abbate A, Testa L, Remigi E, Burzotta F, et al. Compliance with QUOROM and quality of reporting of overlapping metaanalyses on the role of acetylcysteine in the prevention of contrast associated nephropathy: case study. BMJ. 2006;332(7535):202-9. PMID: 16415336.

68. Boluyt N, van der Lee JH, Moyer VA, Brand PL, Offringa M. State of the evidence on acute asthma management in children: a critical appraisal of systematic reviews. Pediatrics. 2007;120(6):1334-43. PMID: 18055684.

69. Braga LH, Pemberton J, Demaria J, Lorenzo AJ. Methodological concerns and quality appraisal of contemporary systematic reviews and metaanalyses in pediatric urology. J Urol. 2011;186(1):266-71. PMID: 21600615.

70. Brito JP, Tsapas A, Griebeler ML, Wang Z, Prutsky GJ, Domecq JP, et al. Systematic reviews supporting practice guideline recommendations lack protection against bias. J Clin Epidemiol. 2013;66(6):633-8. PMID: 23510557.

71. Canter PH, Ernst E. Sources of bias in reviews of spinal manipulation for back pain. Wien Klin Wochenschr. 2005;117(9-10):333-41. PMID: 15989112

72. Choi PT, Halpern SH, Malik N, Jadad AR, Tramer MR, Walder B. Examining the evidence in anesthesia literature: a critical appraisal of systematic reviews. Anesth Analg. 2001;92(3):700-9. PMID: 11226105.

73. Collier A, Heilig L, Schilling L, Williams H, Dellavalle RP. Cochrane Skin Group systematic reviews are more methodologically rigorous than other systematic reviews in dermatology. Br J Dermatol. 2006;155(6):1230-5. PMID: 17107394.

74. Conway A, Inglis SC, Chang AM, Horton-Breshears M, Cleland JG, Clark RA. Not all systematic reviews are systematic: a meta-review of the quality of systematic reviews for non-invasive remote monitoring in heart failure. J Telemed Telecare. 2013;19(6):326-37. PMID: 24163297.

75. de Bot CM, Moed H, Berger MY, Roder E, van Wijk RG, van der Wouden JC. Sublingual immunotherapy in children with allergic rhinitis: quality of systematic reviews. Pediatr Allergy Immunol. 2011;22(6):548-58. PMID: 21919934

76. Delaney A, Bagshaw SM, Ferland A, Laupland K, Manns B, Doig C. The quality of reports of critical care meta-analyses in the Cochrane Database of Systematic Reviews: an independent appraisal. Crit Care Med. 2007;35(2): 589-94. PMID: 17205029.

77. Derry CJ, Derry S, McQuay HJ, Moore RA. Systematic review of systematic reviews of acupuncture published 1996-2005. Clin Med (Lond). 2006;6(4): 381-6. PMID: 16956145.

78. Elangovan S, Avila-Ortiz G, Johnson GK, Karimbux N, Allareddy V. Quality assessment of systematic reviews on periodontal regeneration in humans. J Periodontol. 2013;84(2):176-85. PMID: 22509753.

79. Fleming PS, Koletsi D, Seehra J, Pandis N. Systematic reviews published in higher impact clinical journals were of higher quality. J Clin Epidemiol. 2014; 67(7):754-9. PMID: 24709031.

80. Fleming PS, Seehra J, Polychronopoulou A, Fedorowicz Z, Pandis N. A PRISMA assessment of the reporting quality of systematic reviews in orthodontics. Angle Orthod. 2013;83(1):158-63. PMID: 22720835.

81. Fleming PS, Seehra J, Polychronopoulou A, Fedorowicz Z, Pandis N. Cochrane and non-Cochrane systematic reviews in leading orthodontic journals: a quality paradigm? Eur J Orthod. 2013;35(2):244-8. PMID: 22510325.

82. Gagnier JJ, Kellam PJ. Reporting and methodological quality of systematic reviews in the orthopaedic literature. J Bone Joint Surg Am. 2013;95(11): e771-7. PMID: 23780547

83. Gebel K, Bauman AE, Petticrew M. The physical environment and physical activity: a critical appraisal of review articles. Am J Prev Med. 2007;32(5):361-9. PMID: 17478260

84. Glenny AM, Esposito M, Coulthard P, Worthington HV. The assessment of systematic reviews in dentistry. Eur J Oral Sci. 2003;111(2):85-92. PMID: 12648258.

85. Hu J, Zhang J, Zhao W, Zhang Y, Zhang L, Shang H. Cochrane systematic reviews of Chinese herbal medicines: an overview. PLoS One. 2011;6(12): e28696. PMID: 22174870

86. Jadad AR, Cook DJ, Jones A, Klassen TP, Tugwell P, Moher M, et al. Methodology and reports of systematic reviews and meta-analyses: a comparison of Cochrane reviews with articles published in paper-based journals. JAMA. 1998;280(3):278-80. PMID: 9676681.

87. Jadad AR, Moher M, Browman GP, Booker L, Sigouin C, Fuentes M, et al. Systematic reviews and meta-analyses on treatment of asthma: critical evaluation. BMJ. 2000;320(7234):537-40. PMID: 10688558.

88. Junhua Z, Hongcai S, Xiumei G, Boli Z, Yaozu X, Hongbo C, et al. Methodology and reporting quality of systematic review/meta-analysis of traditional Chinese medicine. J Altern Complement Med. 2007;13(8):797-805. PMID: 17983335.

89. Kelly KD, Travers A, Dorgan M, Slater L, Rowe BH. Evaluating the quality of systematic reviews in the emergency medicine literature. Ann Emerg Med. 2001;38(5):518-26. PMID: 11679863. 
90. Kitsiou S, Pare G, Jaana M. Systematic reviews and meta-analyses of home telemonitoring interventions for patients with chronic diseases: a critical assessment of their methodological quality. J Med Internet Res. 2013;15(7): e150. PMID: 23880072.

91. Kuukasjarvi P, Malmivaara A, Halinen M, Hartikainen J, Keto PE, Talvensaari T, et al. Overview of systematic reviews on invasive treatment of stable coronary artery disease. Int J Technol Assess Health Care. 2006;22(2):219-34. PMID: 16571198.

92. Latthe PM, Foon R, Khan K. Nonsurgical treatment of stress urinary incontinence (SUI): grading of evidence in systematic reviews. BJOG. 2008;115(4):435-44. PMID: 18271880.

93. Lawson ML, Pham B, Klassen TP, Moher D. Systematic reviews involving complementary and alternative medicine interventions had higher quality of reporting than conventional medicine reviews. J Clin Epidemiol. 2005; 58(8):777-84. PMID: 16018912.

94. Lee MS, Oh B, Ernst E. Qigong for healthcare: an overview of systematic reviews. JRSM Short Rep. 2011;2(2):7. PMID: 21369525.

95. Li JL, Ge L, Ma JC, Zeng QL, Yao L, An N, et al. Quality of reporting of systematic reviews published in "evidence-based" Chinese journals. Syst Rev. 2014;3:58. PMID: 24906805.

96. Linde K, ter Riet G, Hondras M, Melchart D, Willich SN. Characteristics and quality of systematic reviews of acupuncture, herbal medicines, and homeopathy. Forsch Komplementarmed Klass Naturheilkd. 2003;10(2):88-94. PMID: 12808368.

97. Lundh A, Knijnenburg SL, Jorgensen AW, van Dalen EC, Kremer LC. Quality of systematic reviews in pediatric oncology - a systematic review. Cancer Treat Rev. 2009;35(8):645-52. PMID: 19836897.

98. Luo J, Xu H, Yang G, Qiu Y, Liu J, Chen K. Oral Chinese proprietary medicine for angina pectoris: an overview of systematic reviews/meta-analyses. Complement Ther Med. 2014;22(4):787-800. PMID: 25146083.

99. Ma B, Guo J, Qi G, Li H, Peng J, Zhang Y, et al. Epidemiology, quality and reporting characteristics of systematic reviews of traditional Chinese medicine interventions published in Chinese journals. PLoS One. 2011;6(5): e20185. PMID: 21633698

100. Ma B, Qi GQ, Lin XT, Wang T, Chen ZM, Yang KH. Epidemiology, quality, and reporting characteristics of systematic reviews of acupuncture interventions published in Chinese journals. J Altern Complement Med. 2012;18(9):813-7. PMID: 22924413

101. MacDonald SL, Canfield SE, Fesperman SF, Dahm P. Assessment of the methodological quality of systematic reviews published in the urological literature from 1998 to 2008. J Urol. 2010;184(2):648-53. PMID: 20639030.

102. McGee RG, Craig JC, Rogerson TE, Webster AC. Systematic reviews of surgical procedures in children: quantity, coverage and quality. J Paediatr Child Health. 2013;49(4):319-24. PMID: 23530924.

103. Melchiors AC, Correr CJ, Venson R, Pontarolo R. An analysis of quality of systematic reviews on pharmacist health interventions. Int J Clin Pharm. 2012;34(1):32-42. PMID: 22183578.

104. Moher D, Soeken K, Sampson M, Ben-Porat L, Berman B. Assessing the quality of reports of systematic reviews in pediatric complementary and alternative medicine. BMC Pediatr. 2002;2:3. PMID: 11914146.

105. Momeni A, Lee GK, Talley JR. The quality of systematic reviews in hand surgery: an analysis using AMSTAR. Plast Reconstr Surg. 2013;131(4):831-7. PMID: 23542254

106. Moseley AM, Elkins MR, Herbert RD, Maher CG, Sherrington C. Cochrane reviews used more rigorous methods than non-Cochrane reviews: survey of systematic reviews in physiotherapy. J Clin Epidemiol. 2009;62(10):1021-30. PMID: 19282144

107. Mrkobrada M, Thiessen-Philbrook H, Haynes RB, lansavichus AV, Rehman F, Garg AX. Need for quality improvement in renal systematic reviews. Clin J Am Soc Nephrol. 2008;3(4):1102-14. PMID: 18400967.

108. Nicolau I, Ling D, Tian L, Lienhardt C, Pai M. Methodological and reporting quality of systematic reviews on tuberculosis. Int J Tuberc Lung Dis. 2013; 17(9):1160-9. PMID: 23809432.

109. Olsen O, Middleton P, Ezzo J, Gotzsche PC, Hadhazy V, Herxheimer A, et al. Quality of Cochrane reviews: assessment of sample from 1998. BMJ. 2001; 323(7317):829-32. PMID: 11597965.

110. Padula RS, Pires RS, Alouche SR, Chiavegato LD, Lopes AD, Costa LO Analysis of reporting of systematic reviews in physical therapy published in Portuguese. Rev Bras Fisioter. 2012;16(4):381-8. PMID: 22858736.

111. Panic N, Leoncini E, de Belvis G, Ricciardi W, Boccia S. Evaluation of the endorsement of the preferred reporting items for systematic reviews and meta-analysis (PRISMA) statement on the quality of published systematic review and meta-analyses. PLoS One. 2013;8(12):e83138. PMID: 24386151.
112. Papageorgiou SN, Papadopoulos MA, Athanasiou AE. Evaluation of methodology and quality characteristics of systematic reviews in orthodontics. Orthod Craniofac Res. 2011;14(3):116-37. PMID: 21771267.

113. Pieper D, Mathes T, Neugebauer E, Eikermann M. State of evidence on the relationship between high-volume hospitals and outcomes in surgery: a systematic review of systematic reviews. J Am Coll Surg. 2013;216(5):1015-25. PMID: 23528183

114. Remschmidt C, Wichmann O, Harder T. Methodological quality of systematic reviews on influenza vaccination. Vaccine. 2014;32(15):1678-84. PMID: 24513008.

115. Santaguida P, Oremus M, Walker K, Wishart LR, Siegel KL, Raina P. Systematic reviews identify important methodological flaws in stroke rehabilitation therapy primary studies: review of reviews. J Clin Epidemiol. 2012;65(4):358-67. PMID: 22360987.

116. Schmitter M, Sterzenbach G, Faggion Jr CM, Krastl G. A flood tide of systematic reviews on endodontic posts: methodological assessment using of R-AMSTAR. Clin Oral Investig. 2013;17(5):1287-94. PMID: 23436119.

117. Seo HJ, Kim KU. Quality assessment of systematic reviews or meta-analyses of nursing interventions conducted by Korean reviewers. BMC Med Res Methodol. 2012;12:129. PMID: 22928687.

118. Shea B, Boers M, Grimshaw JM, Hamel C, Bouter LM. Does updating improve the methodological and reporting quality of systematic reviews? BMC Med Res Methodol. 2006;6:27. PMID: 16772030

119. Shea B, Bouter LM, Grimshaw JM, Francis D, Ortiz Z, Wells GA, et al. Scope for improvement in the quality of reporting of systematic reviews. From the Cochrane Musculoskeletal Group. J Rheumatol. 2006;33(1):9-15. PMID: 16267878.

120. Shea B, Moher D, Graham I, Pham B, Tugwell P. A comparison of the quality of Cochrane reviews and systematic reviews published in paper-based journals. Eval Health Prof. 2002;25(1):116-29. PMID: 11868441

121. Silagy CA. An analysis of review articles published in primary care journals. Fam Pract. 1993;10(3):337-41. PMID: 8282163.

122. Tunis AS, McInnes MD, Hanna R, Esmail K. Association of study quality with completeness of reporting: have completeness of reporting and quality of systematic reviews and meta-analyses in major radiology journals changed since publication of the PRISMA statement? Radiology. 2013;269(2):413-26. PMID: 23824992

123. Weed DL, Althuis MD, Mink PJ. Quality of reviews on sugar-sweetened beverages and health outcomes: a systematic review. Am J Clin Nutr. 2011; 94(5):1340-7. PMID: 21918218.

124. Wen J, Ren Y, Wang L, Li Y, Liu Y, Zhou M, et al. The reporting quality of meta-analyses improves: a random sampling study. J Clin Epidemiol. 2008; 61(8):770-5. PMID: 18411041.

125. Windsor B, Popovich I, Jordan V, Showell M, Shea B, Farquhar C. Methodological quality of systematic reviews in subfertility: a comparison of Cochrane and nonCochrane systematic reviews in assisted reproductive technologies. Hum Reprod. 2012;27(12):3460-6. PMID: 23034152.

126. Xu F, Xiao Z, Zhang Y, Wang Y. Quality assessment for systematic review /metaanalysis on antidepressant therapy published in Chinese journals. International Journal of Pharmacology. 2012;8(7):614-20.

\section{Submit your next manuscript to BioMed Central and we will help you at every step:}

- We accept pre-submission inquiries

- Our selector tool helps you to find the most relevant journal

- We provide round the clock customer support

- Convenient online submission

- Thorough peer review

- Inclusion in PubMed and all major indexing services

- Maximum visibility for your research

Submit your manuscript at www.biomedcentral.com/submit 